\title{
Possible link between anosmia and COVID-19: sniffing out the truth
}

\author{
Annalisa Marinosci ${ }^{1}$ - Basile N. Landis ${ }^{2} \cdot$ Alexandra Calmy $^{1,3}$ \\ Received: 29 March 2020 / Accepted: 3 April 2020 / Published online: 17 April 2020 \\ (c) Springer-Verlag GmbH Germany, part of Springer Nature 2020
}

\section{Dear Editor,}

Coronavirus disease 2019 (COVID-19) is a new respiratory disease that is spreading widely and rapidly throughout the world [1]. The most common clinical presentations of COVID-19 are now well known and include fever, cough, fatigue, headache, gastrointestinal discomfort, dyspnoea and muscle ache [2]. However, we are increasingly observing two additional symptoms in infected patients: anosmia and ageusia. Numerous reports, telephone calls, emails and direct olfactory complaints from concerned collaborators have reached us during the last weeks and our clinical impression is that these symptoms seem to appear late in the course of disease (second-third week) and eventually coincide with healing in patients experiencing mild symptoms. A questionnaire study conducted in several European countries seems to confirm that both olfactory and gustatory dysfunctions are significant symptoms in COVID-19 [3]. Despite similarities between the severe acute respiratory syndrome coronavirus 2 (SARS-CoV-2) and SARS-CoV in sequence, pathogenesis, cellular entry and clinical features [4], anosmia has never been described in SARS.

Anosmia, the inability to smell, is estimated to afflict $3-20 \%$ of the population $[5,6]$ and can result from many underlying diseases. Olfactory impairment after upper respiratory tract infection is well-known and a frequent cause of consultation in specialized smell and taste outpatient clinics [7]. However, the exact location of the damage in postupper respiratory infections remains unknown, even though

Annalisa Marinosci

annalisa.marinosci@hcuge.ch

1 Division of Infectious Diseases, Geneva University Hospitals, 4 Rue Gabrielle-Perret-Gentil, 1211 Geneva 14, Switzerland

2 Rhinology-Olfactology Unit, Department of Otorhinolaryngology, Head and Neck Surgery, Geneva University Hospitals, Geneva, Switzerland

3 Faculty of Medicine, University of Geneva, Geneva, Switzerland biopsies have suggested a direct damage of the olfactory epithelium [8]. A recent study demonstrated that nasal epithelial cells display a very high angiotensin converting 2 (ACE2) expression in SARS-CoV-2 infection, thus allowing wide viral entry [9]. Consequently, peripheral nerve injury might occur causing anosmia, frequently observed in infected patients in our clinical practice.

In light of the striking increase of reports of anosmia in association with the classically reported COVID-19 infection symptoms, we would like to propose the following assumptions:

- Smell and/or taste loss may be a consistent accompanying symptom of SARS-CoV-2 infection. Most observations suggest transient anosmia with recovery after days to weeks, but it remains open in how many cases this impairment remains irreversible.

- It raises the question to what extent the olfactory epithelium could serve as a nose-brain entry path, as this has been suggested in other diseases with accompanying olfactory impairment [10]. Although Li et al. [11] reported that some patients with COVID-19 showed neurological signs, such as headache, nausea and vomiting, it remains unclear if SARS-COV-2 induces short- or long-term neurological manifestations.

- It remains to be seen if anosmia could predict acute respiratory failure in patients with COVID-19 as awareness of the presence of this impairment may have a guiding significance for the prevention and treatment of SARSCoV-2-induced respiratory failure.

Of note, anecdotal reports of this symptom have been recognized as sufficiently serious by otolaryngology societies in France, the United Kingdom and the USA and their members are actively recommended to look for it and to consider any new, unexplained anosmia as a potential COVID-19 case and to take all the necessary precautions. In conclusion, we believe that the scientific community should focus on this accompanying symptom to clarify the role of anosmia in 
COVID-19, instead of leaving this field to the social media. Many questions need to be addressed and patients should probably be tested for olfaction when this is possible. Only a serious follow-up of this clinical observation will help us to understand the sudden rise of anosmia in parallel to the SARS-CoV-2 outbreak.

\section{Compliance with ethical standards}

Conflict of interest None declared.

\section{References}

1. World Health Organization. Novel coronavirus (2019-nCoV) situation report-64 (24 March 2020). https://www.who.int/emerg encies/diseases/novel-coronavirus-2019/situation-reports

2. Xu Y-H, Dong J-H, An W-M, Lv X-Y, Yin X-P, Zhang J-Z et al (2020) Clinical and computed tomographic imaging features of novel coronavirus pneumonia caused by SARS-CoV-2. J Infect 80:394-400

3. Lechien JR, Carlos-Estomba CM, De Siati DR et al (2020) Olfactory and gustatory dysfunctions as a clinical presentation of mild to moderate forms of the coronavirus disease (COVID-19): a multicenter European study. Eur Arch Otorhinolaryngol. https://doi. org/10.1007/s00405-020-05965-1
4. Lu R, Zhao X, Li J, Niu P, Yang B, Wu H et al (2020) Genomic characterisation and epidemiology of 2019 novel coronavirus: implications for virus origins and receptor binding. Lancet 395:565-574

5. Hoffman HJ, Rawal S, Li C-M, Duffy VB (2016) New chemosensory component in the US national health and nutrition examination survey (NHANES): first-year results for measured olfactory dysfunction. Rev Endocr Metab Disord 17:221-240

6. Landis BN, Hummel T (2006) New evidence for high occurrence of olfactory dysfunctions within the population. Am J Med 119:91-92

7. Nordin S, Brämerson A (2008) Complaints of olfactory disorders: epidemiology, assessment and clinical implications. Curr Opin Allergy Clin Immunol 8:10-15

8. van Riel D, Verdijk R, Kuiken T (2015) The olfactory nerve: a shortcut for influenza and other viral diseases into the central nervous system. J Pathol 235:277-287

9. Sungnak W, Huang N, Bécavin C, Berg M, HCA Lung Biological Network. SARS-CoV-2 entry genes are most highly expressed in nasal goblet and ciliated cells within human airways. 13 mars 2020 [cité 24 mars 2020]; https://arxiv.org/abs/2003.06122v1.

10. Doty RL (2008) The olfactory vector hypothesis of neurodegenerative disease: is it viable? Ann Neurol 63:7-15

11. Li Y-C, Bai W-Z, Hashikawa T. The neuroinvasive potential of SARS-CoV2 may play a role in the respiratory failure of COVID19 patients. J Med Virol 2020. [Epub ahead of print].

Publisher's Note Springer Nature remains neutral with regard to jurisdictional claims in published maps and institutional affiliations. 